\title{
Rewarding lifestyles for babies and children wellbeing
}

\begin{abstract}
This article focus on some main topics related to babies' life, infancy, childhood. It is a review of some basic sources of literature about children, and also an opinion summary in which we describe the nociception-beneception balance applied to kids.

The essential theme is that babies, more than any other human being, have the right to life and to wellbeing, since this is an age in which the person has less resilience, the ability to cope with situations, so it is fundamental to live a respected harmonious life, in order to become stronger adults in future.

In this writing we talk about breastfeeding, ideal for the body-mind equlibrium of babies, then about weaning and children diet, and also about crawling and babies development, about babies activities and leisure.

We also distinguish and describe two branches of pediatrics: occidental, that mainly focuses on diseases, and traditional chinese, oriented to giving some tips important to rule a correct lifestyle at any age.

We conclude with a turkish short story tale of Nareddin Hoca, a famous XIII century story teller for kids, always with a taste of happy humor. So as we all have the right to health and wellbeing, children above all have to live an healthy infancy till they are fully mature, and having a guaranteed rewarding lifestyle is a good basis: this is a benefit for every baby and child, and of course for the whole human world society too.
\end{abstract}

Keywords: rewarding lifestyle, babies' life, infancy, childhood, breast feeding, lactation
Volume 4 Issue 2 - 2016

\section{Dora Dragoni, Fatih Divrak}

Nutritionist, Acupuncture and Psychotherapy fellow at AMAB, Italy

Correspondence: Medical Doctor, PhD candidate, Acupuncture and Psychotherapy fellow, Personal and Mental Trainer, Nutritionist at AMAB, Italy, Tel +39-338-508-573I, Email dora.dragoni@studio.unibo.it

Received: January 18, 2016 | Published: February II, 2016

\section{Introduction: lifestyles in childhood'}

As we said childhoood is a determinant age, important for all the years following. So it's basilar that every baby and child can live according to the better wellbeing ideas and practice. Fortunately nowadays we can talk about health understanding, that it is the result of an equlibrium between nociception and beneception, an so: since beneception is ruled by reward system, and being health a right...it's a right living rewarding lifestlyles, according to any age.

We will now briefly talk about children rights, then some chapters will follow: breastfeeding, weaning and kids diet, babies development, motor activities of young people, occidental and traditional chinese pediatrics, and then we will summarize the whole article ideas focusing on reward.

It is at first very important to describe the Convention on the Rights of the Child, CRC, signed by United Nations on 20th november 1989, referred to any young person $<18$ years. It is composed by 54 articles, based on some principles:

1. Non Discrimination - every child has to be respected, no matter the country, the religion, the colors, the language

2. Superior Interest - the babies rights have to have the priority always, in both private and public situations

3. Right To Life and Health - children have the right to grow up in an healthy environment so to guarantee the needed wellbing to all their existance

4. Child Opinion - It is essential to give the best attention to babies and children opionions
In Italy we also have the "natural rights of kids", 10 ideas good to follow, such as: the right to relax spending time not ruled by adults, the right to dirty playing with natural environment, the right to live in nature smelling grass perfume for example, the right to a good dialogue, the right to play games using also hands (like those with natural materials), the right to have a "good start" (eating good food, drinking healthy water, and breathing natural air), the right to play and live outdoor too, the right to spend time in natural envoronments, the right to silence and to natural sounds (like wind and water), the right to observe natural phoenomena.... Since a good childhood is basis for our whole life.

We can summarize those rights into the Right To Reward since as we will describe: our health condition is based on two opposite sides... nociception and beneception, and it's our right to stay healthy (Word Health Organization), that means live in wellbeing, that corresponds to accomplish to our reward needs.

\section{Breast feeding and lactation ${ }^{2,3}$}

Mother milk is a complete food, containing all the needed nutrients such as: proteins, vitamins, water, sugars, minerals, hormones, immunitary molecules; it is able to reduce the perintal and infancy morbi-mortality. It is also a great moment of affectivity and satisfaction between mother and baby. It is fundamental to know that artificial milk cannot be compared to mother milk.

According to UNICEF and FAO: it is fundamental to breastfeed babies till the 6thmonth, and this is to continue till over the 2 year of life. It is also important to assure the basic assistance to each mother in every phase of pregnancy and puerperium, lactation included. 
There are lots of advantages of breastfeeding for both mother and baby. There are health advantages, nutritional, immunologic ones, psycho-social ones, economical and environmental too. In the first 4-5days colostrum is the main milk produced by mother breast. It is rich in antibodies, in proteins, vitamins; it is for all these reasons also called "first vaccine". It also help intestinal function of baby, so to evacuate meconium. From the 15 thdays the milk is a complete food for the baby. It is called "initial milk". It contains more lactose. Final milk is more calorical and it also help in satiety sensation of baby.

Human milk is rich in essential fatty acids, like arachidonic acid, great for brain functions. Lactoferrin and vitamin $\mathrm{C}$ help in iron metabolism. $87,5 \%$ of water helps in a correct baby hydratation.

It also prevents infections and reduces the baby mortality. Physical interaction of mother-baby helps the production of oxytocin, fundamental from a physical and psychological point of view.

Mothers who breast-feed have less risk of breast cancer, of endometrium, of ovary (expecially if breastfeeding lasts for more than 8 months). Babies cries less if breast feeded, thanks to the love that this situation involves.

Breast feeding also helps the whole family, since it's great from a psychological point of view, and also from an economical aspect. Milk production is due to prolactine: since the placenta is expelled, there is a sudden reduction of oestrogens and progesterone, so that prolactine increases and milk starts being secreted by breast glands. The more the baby is breast feeded the more milk is produced, due to local cutaneous reflexes of mother breasts leading to more oxytocin mainly, so to expel more milk for the baby. Breast feeding during night can help the production of more milk too.

Of course any good feeling helps, any negative condition reduces the milk production. Usually mothers breast feed sitten, or this can also done in lying position, with baby lying in bed and mother near him. The baby has to keep in his mouth the more breast portion he can, so to have an efficacy suction and milk production and ejection. The baby suction of biberon is different and it can confuse the baby.

It is important to breast feed at least every 3hours. In the first 5 minutes baby eats $80 \%$ of breast milk. Breast feeding mother has to follow some lifestyle rules, such as: 6-7 meals per day, more water intake, evitating foods giving flavours to milk, no alcol, no smoking. The mother can do fitness activities. She can uses absorbents for breast to reduce skin lesions, use comfortable underwear, evitating any medical drug, and of course cleaning often the breasts. Of course fissures and mastites can take place. Baby can have colics and crying too.

Mother should know that baby in the first 10days loses $10 \%$ of his birth weight. Human milk can be manually extracted and preserved in glass or plastic containers, and in biberon too in $60-120 \mathrm{~mL}$ portions, with the date of the milk, in fridge and freezer and then prepared at $37^{\circ} \mathrm{C}$ in bain-marie.

To increase milk production it is basic to reduce stress and increase the contacts between baby and mother. Acupuncture can be galactogenic, a part from if some drugs are used. In TCM tradition there are points great for lactation, both thoracic (local) points and both general points, that can help for example chong mai, an extraordinary meridian regulating breast function, or some other points specific for that; women confirm the increase of milk production.

Milk can reduce when the woman comes back to job. Another interesting topic could be contraception during breast feeding, since woman can be fertile: of course it's better to avoid hormonal ones.
It is important to spread a breast-feeding culture and to know and develop breast-feeding laws. Lactation and breast-feeding are human rights, baby rights, mother rights...this according to WHO and UNICEF since 1996.

\section{Diet and nutrition}

\section{Diet in infancy ${ }^{4}$}

In the first year of life weight increases by $300 \%$. In the first 3 months of life $35 \%$ of energy is used for growth, and $3 \%$ at 12 months. If we compare the baby diet to the My Plate diet (see my article in MedCrave "Diet, health and wellness"), this has to be richer in fats and lower in fibre. At age 5 the diet is almost similar to adult one. There are formulas to predict baby's height, taking into consideration parents height and similar datas.

There are also tables useful to calculate: how many chalories are needed in every group of months (more than 100 chalories $/ \mathrm{kg} /$ day at $0-3$ months, 95 chalories till 3years and so on), or the grams of proteins: $2 \mathrm{~g} / \mathrm{kg}$ till 3 months, then $1,5 \mathrm{~g} / \mathrm{kg}$ till 12 months and so on.

There are also growth charts to compare. Every baby should be measured every 7 weeks, not more frequently to reduce hypothetical anxiety. Breastfeeding is the better choice as we said. We can focus on some important concepts again.

Colostrum is produced for 1-3days. In 3 weeks mother gets to mature milk. Mother milk contains protective factors:

i. Immunological components: lactoferrin, lymphocytes, Ig, bifidus factor

ii. Essential fatty acids: DHA useful for CNS and retina

iii. Structured fats

iv. Proteins

v. Nucleotides

vi. Prebiotics

Breastfeeding also encourages bonding between mother and infant, it's helpful for woman to control weight, suppressing ovulation helps iron stores return to normal, it's free and many other ideas we already know. Also for the infant it's great, it reduces infections, and it's great also for baby wellness, it's linked with less obesity in later years.

There are positions to breastfeed: sitting, backwards, propped up and lying on side, for example. It's important to breastfeed "as often as the infant wants". And it's fundamental to always offer both breasts at each feed.

A breastfeeding woman has to: follow the My Plate suggestions + drink at least 2 liters water and:

i. Add $450 \mathrm{kcal}$ for first month, 530kcal for month 2, 570kcal for months 3-6

ii. Add also 10 grams proteins per day

iii. Eat 70mg vitamin C, 10 micrograms vitamin D, 1000 micrograms vitamin A, 260micrograms of folic acid, $1 \mathrm{mg}$ of thiamine, $2 \mathrm{mg}$ of riboflavine. Also avoid alcol and caffein. Avoid spicy foods. Breastfeeding milk is $70 \mathrm{kcal} / 100 \mathrm{ml}$.

Bottle feeding is also important: after 1months of breast feeding only, it can be needed to bottle feed.

I. Whey dominant or first stage milk... whey:casein 60:40 
II. Casein dominant or second stage milk... whey:casein 80:20

III. "Follow-on milk" or third stage milk and toddlers milks: with additional vitamins and minerals and lower sodium for example.

Soya milk is not good before 6months as goat milks (not enought studies).

\section{Weaning}

At 6 months solid foods can be added into infant diet. At the beginning: pureed and mashed fruits, vegetables, rice, potato. Foods containing iron. All foods can be offered 2-3times every day. It's always important to follow also baby's attitudes.

When baby is $1-5 y e a r s$ old are suggested:
a. All fresh fruit
b. Popcorn
c. Carrot and celery
d. Plain biscuits
e. Cucumber
f. Tomatoes
g. Olives without stones
h. Cheese
i. Yogurt and soft cheese
j. Milk
k. Hummus
1. Sandwiches and toasts
m. Rice cakes

It's better to avoid: eggs, fish, honey for botulism, nuts for choking risk, salt, sugar, too many fibres, low fats and low energy foods. Pay also attention to some foods, that can be allergen, such as: milk, mustard, eggs, peanuts, fish, wheat, sesame, lupins, celery.

\section{Child nutrition ${ }^{5}$}

Child nutrition varies from country to country. In Occidental World babies and children are overfed. On the contrary under-resourced areas infants can suffer from under-nutrition. The common trait is that children as all other living creatures prefer eating socially.

Another difference is snacking: in Europe is less frequent. The problem is that in US the governement incentivize farmers to gro corn and soy, so snacks are made with these products being them cheaper but also too many times processed.

The basis is feeding our babies with love. Breast feeding is of course fundamental. And it's stimulus dependent: that means that the more babies needs milk and asks for it, the more mother can produce. It's a sort of synchronized reflex. The baby sucks, hypothalamus is stimulated, oxytocin is released and produced. Prolactin too increases the production of more milk. It's called the "let-down reflex".

Breast feeding, as we previously told, has unique benefits for the infant and the mother too. Baby passes from sterile uterus to an environment full of pathogens. Colustrum is already rich in antibodies and then we pass to mature breast milk, higher in sugar and fat. Infants fed with mother milk are less obese and have less risk of Sudden
Infant Death Syndrome. Mother too gets benefits: it has a positive cost-effect rate, it helps birth-spacing. The skin-to-skin contact leads to more succesful bonding and improves overall health. If the mother breastfeeds for more than 8 months, many cancers are really reduced, as we said, such as: breast cancer, ovarian cancer, osteoporosis. The community too gets benefits: less pollution, and less costs for health problems, since wellness is better with breastfeeding. Vitamin D supplementation is reccomended during exclusive breastfeeding.

\section{Introducing Solids}

The first choice can be: pureed vegetables. They have fibers and are better to prevent high blood sugar rates, that can on the contrary be a risk with white rice. Talking about the flavors: sweet potatoes, avocados, peas, bananas.

In Turkey it's typical to prepare for babies: labneh (yogurt dish), home made yogurt, egg yolk, mashed apple, banana and pear.

a. In Japan there is Okuizome: 100-120days after birth. It contains rice, fish, vegetables.

b. In Kenya first food are sweet potatoes.

c. In Jamaica: pureed papaya, banana, mango.

d. In China: rice, fish, carrots, seaweed and eggs.

e. The Hindu first meal is "annaprasana": rice porridge blessed by family.

What is fundamental is: eating 5 servings of vegetables and fruit per day of all the colors (essential for all kind of vitamins daily intake). For example vitamin $\mathrm{A}$ is in oranges, sweet potato, carrots, apricots, or in green ones such as spinach, broccoli etc.

During the first year it's better to avoid: honey due to botulism; home canned foods; milk that is difficult to digest; fish, containing mercury; high-sugar and high-salt foods. Another suggestion is sitdown. Also important is: preferring home-made foods.

Talking about growth: it's related with development. An healthy diet is based on vegetables and fruits. It is important to distinguish basic concepts of nutrition and dietetics: such as choosing low glycemic index carbohydrates (not refined not preserved but raw). Proteins are essential for babies growth, and we can choose also plantbased ones such as: tofu, nuts, beans, lentils. Fats can be also good, as in case of unsaturated fats (like olive oil).

Drinking water is great. Evitating salt is important too. Stevia can be a good natural sweetener. It's important to train children to prefer healthy foods, since what they learn to eat in childhood they will go on choosing during their whole life. Healthy and varied diet is great for health and wellness.

Food marketing is to analyze and know since it's a risk for babies. Marketing presses on fast food, sweet food, cola and soda drinks. Package is also studied to be liked by babies. At the supermarkets babies foods are near to children eyes in the closest shelves. There can also be gadgets included. The healthy hunger free act of 2010 improved the quality of school snacks: we pass from chocolate and candies snacks with more than 200 calories... to cereals snacks, that are around 100-150 calories.

Food allergies is also a diffusing topic, since $5 \%$ of population suffer from that. The most common allergenes are: milk, eggs, peanuts, soy, fish, shellfish, wheat. It seems that gut bacteria are responsible for that, and also the excessive prescription of antibiotics. 
Childhood obesity is epidemic as well. In 2014 more than $2 / 3$ of population was at least overweight, with a $300 \%$ increase in 40 years. The risk is that this generation could live shorter lifespans than their parents. It's important to check BMI, body mass index, that is good if 18,5-25 (mass in $\mathrm{kg} /$ height in $\mathrm{m} 2$ ).

Diabetes is of course a comorbidity, and parents role is always fundamental, so to hel children doing the right nutritional choices. Adequate sleeping is also a way to regulate emotional eating. Infants who sleep more than 10 hours per night are less overweight.

Local and organic foods are always to prefer, particularly with babies. It's a way to support our community, it's fresher, it impacts less with lower carbon footprint, it's affordable, and you can check where the food comes from.

Organic means $=$ no use of synthteic pesticides, no synthetic fertilizers, no GMOs, no iradiation, no sewage sludge. We can also talk about CSA, community supported agriculture, that gives you the possibility to buy and receive directly at home the order that you paid. Hormones too in food shoul be avoided, and also antibiotics.

The Global Footprint Network is a way to follow the whole path that your food is doing from production in farms to your shop, to track and check the quality of the food. For example cows can be raised in pasture and not in CAFOs, confined animal feeding operations. Preferring vegetable food is also great since it has the lowest associated greenhouse gas emissions. Sustainable seafood is important as well: we mean that we should save food sources.

Whild doing food shopping:

i. You should go with shopping list to evitate unuseful food

ii. Be aware that the more easy-to-pick food are those less healthy most of times

iii. Check the labels, to evitate preservants and choose more healthy food (less fats for example)

iv. ... and at home carefully wash the food like fruits and vegetables, and preserve them correctly as well. Choosing also the best cooking ways is important.

If we talk about healthy prenatal diet for pregnant women, we should include:

I. Vegetables: carrots, broccoli, lettuce, cucumbers, cauliflower, eggplant, onions, garlic

II. and: fresh herbs, mushrooms

III. Fruit: oranges, apples, pears, peaches, pineapples, mangos, brapes, lemons, limes, bananas, berries

IV. Grains: brown rice, whole wheat pasta, quinoa, millet, oats, cornmeal, whole wheat bread, farro

V. Proteins: eggs, beans, lentils, nuts, tofu, fish, chicken and white meats, dairy products

Following the MyPlate diet is a good idea. Avoid also: alcohol, soft cheese that can lead to bacteria risk for woman and babies, or also undercooked animal foods.

For pregnancy craving try to prefer key nutrients, such as spinach, rich in folic acid and iron. Salmon is fundamental since it's rich in omega- 3 and it's also lower in mercury. Use table salt rich in iodine, so to help baby development. Save your vitamin D intake exposing at sun and always remember that cooking together strengthen children relationship with food and it also protect everyone's health.

\section{Baby development ${ }^{6}$}

The development of baby is based on: safe living, optimal care, good food, clothes, life at the open air, activity vs rest, prevention of risks, education to a correct lifestyle. So a great part is based on: affection, individual care, security based on the relationships to which the baby belongs, sense of personal identity and of dignity, and occasions to get life experience.

Indeed difference between "growing" and "development" is: not only growing of height and weight, but also of the functions involved for a human being. We can include also: motility, vision, hear and language, affective behaviours. It is clear that both genes and environment are involved in all these phoenomena.

It is important to observe some reflexes: sucking, deglutition, defecation. Then the baby looks at lights and movement, and listens to sound, stopping his activities to do that. Another characteristic common to all babies is that they pass to the prevalence of sleeping time to periods of wakefullness.

At 1 month the baby has a reflex of automatical march, and he tends to make steps toward an obstacle. He is able to close eyes if a direct light is directed toward him. He cries if he is hungry or in case of some symptoms. At 6 weeks he can smile. He starts to respond to stimulations as bath moment.

At 3 months he plays with his fingers. He starts to keep his head up during prone position. If a ball is approached to him, he fixes it. He is able to keep in hands a toy. He can react with joy to happy approaches to him.

At 6 months he plays with his feet. He is able to move his shoulders to get sitten. He moves his arms in prone position. He can keep his weight balanced on the legs if helped to stand. He can have parachute reaction. He is able to put objects from an hand to another. He can observe balls moving at 2-3 meters far. He can react with joy to active happy plays toward him. He turns his head if a toy sounds near his ears. He is still social with unknown people.

At 9 months he plays with toys. He starts to crawl. He can stand, leaning on stable objects, he starts realizing more complex plays with toys. He starts imitating voices he hears. He locates sounds far from his ears, but not on the midline. He can play a bell. If an object is partly hidden he finds it, but not if the object is totally hidden and he cries.

At 1year the baby can crawl and even walk. He turns his head to any voice. He starts using common daily life objects. If sounds are repeated he is not interested. He claps his hands. He can find hidden objects.

At 15 months he can walk without help. He can build towers with two cubes. He uses common daily life objects. He can make drawing signs with a pencil on a paper. He can push a toy on the floor.

At 18 months he can walk with a toy in his arms. He can jump into the adult chairs. He can walk the stairs with an adult. He can get balls far from him 3 meters. He builds towers with 3 cubes. He can observe pictures in a book. He starts learning a rich vocabulary to talk. He can indicate parents noses. He plays alone moving objects. He can open a door. He is still dependent to familiar adults.

At 2 years he can walk the stairs. He can kick a ball. He can ride a bike but only walking. He can build towers with 6 cubes. He can make scribbles on a paper. He can use a cup. He can wear a hat and shoes. He doesn't play with other babies even if he can play near them. 
At 30months he can make "V" signs in a paper. He observes books with stories. He can walk stairs holding toys. He can stand on a foot.

At 3 years he builds towers with 9 cubes. He can build bridges of cubes. He can copy a circle on a paper. He can cut with scissors. He can use a towel and is almost autonomous in his bathroom personal hygiene, this ability being better at 4years.

Then the abilites go on and for example at 5years he can take care of younger brothers and sisters, or other babies.

\section{The young champion ${ }^{7}$}

Now we will talk about motor characteristics and abilities of babies, children, and adolescents as well.

We can do some definitions. We call a baby "newborn" or infant till he is 4 months old.

a. Childhood or infancy: till the baby is 2 years old

b. Puberty: 10-17years

c. Adolescence: 14-21years.

Talking about motor development, it takes place particularly in the first years of life of a baby. The baby learns to walk, jump, run, throw objects-balls, and so on.

There are several degrees of motor development:

a. 1 year: crawling, coordination, sit, movements related to emotions

b. 2 years: run, dexterity, posture

c. 3 years: better walk, prehension, equilibrium

d. 4 years: great dexterity, climbing

e. ...then 7years: sport games, and 9-10years: team sports. Babies learn some abilities: structural, functional, articular, and sport abilities.

Coordination is quite difficult, since it involves the integration of many stimuli: motor and sensorial ones, sensations and perceptions, these related to the conscience of sensations. All the senses are involved: the 5 senses, then proprioception, and the sense of staticdynamic.

Other skills are: ability of motor learning, ability of motor control, ability to adapt and transform movements. Then dexterity (for fine movements), ability to combine movements, rythm ability, orientation ability, memory about some movements series, and "the ability to foresee a movement" (this is very important since it involves Intuition), equilibrium (static, dynamic, and during flight, that is in every moment in which we are not in contact with ground), and motor fantasy.

Some exercises that can be done:

i. Dribbling even on one foot only

ii. Dribbling in slalom

iii. Following a line on the ground with the ball

iv. Burst soap bubble

v. Jump on mattress

vi. Jump the cord

vii. Run but changing speed for example viii. Walk maitaining equilibrium

ix. Jump on a foot only

Then some dexterity texts can be done. When the baby is:

a. 0-2years - sensory-motor phase - he refines reflexes and automatical movements

b. 2-7years - preoperatory phase - concrete activities learning starts, and the baby learn symbolic games

c. 7-11years - concrete activities phase - empirical phase, then learning improves in the following years.

The perception of the body also takes place, such as body scheme and motor schemes. This is a parallel phoenomenon to personality and affective constitution. Cybernetic says that movement is only the adaptation to an environment.

Some exercises can also be:

a. Before run, then relax on a carpet so to feel our breathe, heart beat and body perceptions

b. While the child is on a carpet, moving his arms while he percieves the movements

c. Creating paths in which run freely.

The development phases are the same as previously told, particularly:

i. 10 months: the baby can manipulate objects

ii. 1year: crawling is at its best

iii. 15 months: orientation is good

iv. 18 months: the baby has not yet learnt a laterality

v. 24months: deductive movements can be done, such as moving a chair

vi. 5years: basic motor schemes are learnt; edipic phase

vii. 6years: equilibrium is good

viii. In puberty: egocentric phase

Parents can also check some points to exclude autism risks, such as:

a. If the baby like parents contacts

b. If the baby is interested toward other babies

c. If the baby likes climbing

d. If the baby does symbolic games, such as cooking

e. If the baby is able to indicate

f. If the baby shows objects and games

Symbolic game is also important:

a. The baby understands the functions of objects

b. The baby starts simulating

c. The baby simulates on others the game

d. The baby can simulate this play with other objects

Talking about emotions they also starts being percieved: angriness, happiness, fear arte the first: they are innate and due to genes. There 
can be group exercises related to this: the babies have to express with mimic the emotions expressed and then hug between them to feel better, for example, and maybe walk through paths with ninepins. 3years is the medium age in which a baby has a dexterity: $90 \%$ of babies are right-handed. This can be verified even with some tests, for hands or even for eyes prevalence.

Talking about training: it's great to train children abilities in the 3-8years ages, particularly coordination. At 8years it's good to train equilibrium, then speed and strength. At 13years it's important to train articular mobility, strenght and resistance. During infancy it's fundamental to train in a light game mood.

According to some tables written by Martin in 1980:

A. Motor learning abilities start a 7-10years, particularly about rapidity, resistance, focusing on mobility, dexterity

B. In the second "scholar age" all the techno-motor processes are developed: and there is difference between males and females; speed strengh improves, time reaction reduces so to get values similar to adults, and resistance can also be anaerobic; perceptions are good too

So, to summarize, according to Atleticastudi:

a. 6-8years is an age in which the kids learn phyical activites relating these to play and games

b. 9-11years is an age in which exercises can be done, at natural weight lifting; equilibrium is to be improved

c. 12-14years: more complex acrobatic exercises

d. 15-16years: general and special exercises

During a motor task, the baby should:

1. Organize the motor task

2. Getting all the elements of the task

3. Moving into the environment

There are then cognitive and motor abilities, and they are single abilities and in series too, and continuos. Automatism is later learnt as well, after the repetition of the athletic act.

There are some abilities: conditional abilities (strengh, resistance, speed), functional abilities (articular mobility and coordination). Every ability has its own specific tests.

Strength increases from 10years to 18years, and it's somehow testosteron related. At 16-17years the weight lifted can join the body weight of the athlete. Speed strengh is influenced by neuromotor evolution and coordination. Only at the end of puberal age all this is at its maximum. At 15-16years "overloads" can be added.

Resistance can be specifical or general; short, medium and long resistance; speed resistance, strength resistance. Aerobical resistance, related to lattacid individual power.

Speed can be distinguised from rapidity (related to a short period of time) and from explosivity. It can be cyclic, resistant, of action and of reaction, and complex. At 15-16years the ability, from a lactacid point of view, becomes similar to adult.

Articular mobility increases thanks to collagen, and stretching is fundamental. At 6 years the mobility is already great. At 15-16years training can be focused on that.
Feedback is important in every training, and it is related to the effects of sport actions, that can be evaluated by the kid. It is basic to know the effects, such as: 1 the performance 2 the result. Positive and negative reinforcements are the key mechanisms.

Another important message is: every match is not determinant, since it has to be seen as a pedagogical event for the athlete, particularly in youth.

\section{Occidental pediatrics ${ }^{8,9}$}

We will now talk about some useful ideas taken from a traditional occidental pediatrics textbook for Medical Doctors.

One of the first points are Vaccinations. This is a controversial topic but in lots of cases vaccines can help improving babies health. Every country has its own mandatory vaccines and suggested ones as well, according to timetables that involve the baby at 3months, 6months and 1year more or less. Usually they are grouped together since it's common known that immunity is strongly stimulated in this way. The most important are: HBV, DTP (diphteria, tetanus, whooping cough), MPR (measles, mumps, rubella), poliovirus. Then some general data follow: as proportions in newborn (head $=1 / 4$ of body), $50 \mathrm{~cm}$ lengh, $36^{\circ} \mathrm{C}$ tempetature at birth etc. New born can have physiological jaundice. There are common reflexes too.

Endocrin system starts to be more mature starting from 6th month: at birth gonadotropin are high as ACTH, the stress pituitary hormone. And then growth is due to GH only starting from 6thmonth.

Then follow classical ideas about occidental classification of diseases. A good pediatrics text is also Nelson's Pediatrics. We will review some chapters that we consider important and useful, and we hope interesting as well.

\section{The healthy baby}

\section{Diet and nutrition}

In the first year the main chalories sources are mother milk and artificial milk, then baby can start drinking cow milk; later on, cereals and solid food.

In this months during pediatric visit it's good to measure body weight and also height growth.

It's fundamental to create a good equilibrium between parents and baby, and parents have to pay attention to the way of reaction of their kid; it's also good to prevent stress situations. Playing games and playing with little books can help. During the first 24 months the baby grows more fastly.

\section{Growing and development}

Biological influences are: genes, teratogens, post partum diseases, and other noxious stimuli. During the first year of life the baby starts building the basal confidence, that as we know is related to oxytocin. And a psychology branch study that: it's a science noticing how the affective relationships between parents and baby is basis to create a strong baby's mind, thanks to correct bonding for example. So affective and emotive life are fundamental. Attachment can be seen when baby looks for parents in case of need; of course adults have to give good answers.

The relationship parent-baby is important to overcome negative events and to build up correct behaviours and learning. It's important to give correct parents reactions also to non verbal interaction. 
The first year of life is characterized by basal confidence (Erikson) and cognitive-emotive and motor growth (Piager).

\section{First phases}

In first week: implant. Then: endoderma and ectoderma start creating. Mesoderma starts when woman is aware of being pregnant since she doesn't have cycle bleeding. Soon the embryo starts having human aspect, with limbs; he is $4-5 \mathrm{~mm}$ long. Eyes, mouth and hand fingers start too. Nose creation takes place when the embryo is $22 \mathrm{~mm}$. Genitals too start.

Then fetal phase starts. The baby is $5 \mathrm{~cm}$ and 8 grams. Before third semester he is 800 grams and $20 \mathrm{~cm}$, passing to 35 after the start of the third semester. Then eyes open, and in this period fetus is $25 \mathrm{~cm}$. At 38 thweek baby is born.

Fetus in third trimester has changes in heart rate, in parallel way to movements that he can do, due to variations of mother's states or sounds. As soon as fetus starts to move, parents begin to have thoughts about how they will behave as parents and so on. It's always important to build a good connection with the partner in order to be stronger and more loving parents.

\section{The newborn}

The skin-skin contact of mother(and even father)-newborn increases breastfeeding months time. Almost immediatly after birth, newborn is wakeful and he can suck mother's breast. He can see 20$30 \mathrm{~cm}$ far, that means the distance between him and mother's face. Hearing is good developed and he prefers female voice. The first changes are: lung ventilation, redistribution of circulation, intestinal activation.

The right equilibrium is needed, between sleep and wake. It's important to awake and wake up in order to eat. If baby is too active he can have skin flush, pale skin, hiccough, vomit, weeping crisis, and so on. If newborn is hyperstimulated he can suck his fingers, to destress.

It's fundamental that mother gives good, positive and affective feedbacks to baby, so that he/she has an ideal inner development. The mother is the one able to decrease tension for example, in case of strangers talking and referring to baby. It's basilar that mother and baby get relaxed together. It's also essential to dress the baby in the most correct way.

\section{The first year}

In the first year of life the most important changes take place, fundamental for the correct basis of the future years too. In the first year we can observe: physical development, acquisition of new abilities, inner organization.

\section{The first two months}

i. In the first week of life, baby's weight can decrese of $10 \%$, due to liquids elimination and for an eventual reduced chalorical intake. By the 2ndweek baby gets new correct weight.

ii. In the first month the increase is 30 grams per day.

iii. Baby can smile but in a not conscious way.

iv. On the contrary are conscious: looking, head rotation movements, sucking.

v. Baby usually turns toward his mother.

vi. It's important to keep the baby awaked during day so that night sleep is better. vii. During night, babies can sleep 6 hours, others need to eat 2-3times.

viii. The reaction to stimulus is variable: some babies can search stimuli, and usual all get adapted to repetitive stimuli.

ix. It's essential that the baby sees that his needs are always satisfied, so that he can build confidence.

x. It's also good to pick the baby up: in this condition babies stop weeping at less that 1 year.

xi. It is important to regulate eating timetable.

xii. In case the mother has somekind sad moments after birth: it's due to hormonal situation and it solves after this normalization.

\section{2-6months}

a. In this months baby starts to smile consciously, he aquires motor and cognitive abilities.

b. At $3-4$ months baby grows 20 grams per day. In the first 3 months he grows 1 kilo every month. At 3-9monhts he grows 500grams every month.

c. Arcaic reflexes disappear.

d. Baby sleeps on his side, more frequently.

e. Vision sense is deeper as well.

f. Baby sleeps 15hours per day: 9-10 during night. Sleeping EEG is mature.

g. At 4 months newborn is interested toward external world

h. During breastfeeding he can distract too.

i. He starts touching his own hands, ears, cheeks, and genitals too, and he can make bubbles.

j. He acquires sensations and perceptions.

k. It's also common observed that baby can synchronize his expressions with the adults he has near.

1. The energy of the baby is linked with the time spend in happiness with parents, for example: this is a basis to understand and in order to apply reward.

$\mathrm{m}$. He is also able to give answers to affective behaviours we can demostrate to him.

\section{6-I 2months}

There is an increase of motor activity and progresses in communication can be seen.

a. Baby starts to realize his needs.

b. At 7 months he can sit without help.

c. At 8 months he crawls and trys to stand up.

d. At 9 months he can realize clamp prehension.

We can say that motor abilities are parallel to myelination of neural fibers and to cerebellum development. Teeth development begins from inferior incisors, and it's linked to scheletrical development and bones growth.

Initially "foreign" objects are gobbled. Then they are inspected, and baby plays with them with his hands, beating surfaces eventually. They can also be shed. 
At 9month baby learns that objects exist even if they disappear from view.

I. If we hide objects from baby, he looks for them.

II. Baby lives negatively when parents go away from him some hours.

III. Even in night he can awake and he needs parents near him.

IV. He starts also to need autonomy, particularly when he eats.

V. He can weep and cry when his willings are not done.

VI. At 7 months he communicates mainly in a non verbal way.

VII. At 9months he can trasmit his emotions.

VIII. At 8-9months he can say syllables, such as: BA-DA-MA.

IX. It's good to use illustrated and painted books, to learn verbal language.

X. At 9 months baby can have eating and sleeping alterations.

XI. Before his first birthday, baby can drink from his glass.

XII. If the weight increase is low, it means that baby is living in stress condition.

XIII. Baby has a bit fear of foreigners and he needs lots of autonomy, and this is a pillar to respect.

\section{Oriental pediatrics}

\section{Pediatrics in traditional chinese medicine ${ }^{10}$}

Children in traditional chinese culture correspond to spring, to dawn, to the groth of yang into yin, to wind. They tend to get sick but they recover very soon. It's due to their dynamic energy sistem, and qi (the overall energy) can be re-balanced.

Usually pediatric oriental medicine bases on TUINA, the therapeutical massages. When the kids get older needles can be used as well. Usually people apply to chinese medicine for babies when traditional medicine is lacking. TCM is able to solve "knots", to free accumulations, to tonify, to strenghten, so to get to armonious growth. It is useful also in recurrant and chronical illness. It is good for colitis for babies and changes in bowel habit, to babies insomnia, regurgitations, enuresis, etc. Acute symptoms get better soon, chronical maybe need more time. Sometimes it's also important to give adviced to parents regarding their own lifestyle. The theoretical basis are the same as those of acupuncture and TCM.

Tuina: The methods ("fa") are: knead ("rou"), and push ("tui").

They are based on pressing on skin with one or two fingers, following a line or circles. Another method is based on rubbing down the skin, or creating waves in skin.

Secondary methods: creating circles in two senses; pinching the skin; massaging in circles, patting on small skin areas.

For example: BAGUA, on hand palm, stimulating a circle against qi stasis. Shuidi Laoyue, fishing the moon in water, arch line in palms of hands, to reduce heat. Sanguan, the three gates, on radial side of forearm, in proximal direction, to tonify qi and yang, against cold and empty (cough, diarrhea). Tianmen, the door of the sky, at the center of the forehead, to calm shen; or Kangong, water palace, a line over eybrows, to act on XIE pathogens and flegm: Xinmen, heart door, at the top of forehead in center, to calm shen.
Then all the main points used for adults, like back shu and so on. Some have different names or extra names.

Moxibustion: ...can also be used, paying attention not to burn skin. In case of qi xu deficit it can be used also in babies (or even in jing xu in puberty, for development delay).

Guasha: As in adult, it is based on stimulating the skin with a massage done with GUASHABAN, a sort of spatula, till that some red signs are visible on skin; in kids the signs are to be lighter. It is great to disperse heat.

Cupping: Cups were taken from animals horns, later in bamboo or glass materials.

If the symptoms are related to a "fullness": strong cupping is needed; if "empty": light cupping is better. In pediatrics: glass cups, with light stimulation. It is good in: asthma and allergies, to act on back shu points.

Diet: Preferring cooked foods is fundamental, evitating very cold ones. It's important to reduce extra meal foods, and to eat in calm way.

Preferring local foods too is great. Evitating too: strong flavours, such as too sweet foods, hot spicy foods; preservants, fried foods.

Mother milk comes from transformation of xue, the blood. After 6 months the blood goes back to uterus. Weaning consists in passing to more complex foods, changing in food consistency, and changing in foods temperatures. Rice and carrots are a great meal, for example. Another example: to tonify qi is important to eat mildly sweet foods, and add even some hot spicy flavour. To move qi: hot, spicy and moderate acid flavours, maybe a bit cold. Against the XIE = external pathogens, opposite foods are indicated: cold or hot ones, and bitter foods can purify as well. Some ideas are:
A. Rice soup
B. Vegetal broth or soup
C. Vegetables cream
D. Millet with vegetables soup and parsley or marjoram

E. Sweet soup: with apple, grapes, corn, hazelnut cream too

F. Vegetable soups with cerely and laurel

G. All these are great for babies less than 1 year old

$\mathrm{H}$. When the baby is 1-2year some other recipes can be done, adding flavours, such as:

I. Indian soup: with ginger, cloves, cardamom, coriander

J. Or fish cooked in many ways

As we see traditional chinese medicine, and it's also true for any oriental systemic health system like for example ayurveda, it's fundamental to focus on correct lifestyle, and all therapeutical systems are there only to Rebalance the needed equilibrium. This is a traditional approach dating back 5000-3000years ago, and also redescovered by social medicine expert and researcher Antnovsky in $1970-80$ s, as we will tell later.

\section{Summary \& perspective ideas: reward for wellness ${ }^{11}$}

In the core of the article we talked about babies breastfeeding, babies weaning, babies development phases, babies motor abilities 
and some kind of fitness they can follow; then i talked about occidental and oriental approaches to infancy from a medical point of view.

The message that we want to give in this article is that, particularly during infancy, it is fundamental to relate with babies being conscious that reward is the main need that babies have, as anyone of us.

\section{Reward System}

In other previous articles the attention was focused on reward system since it is the key to explain how health is based and how it can be reached and maintained, so to live in the most wellness condition that we can.

\section{It's common known that brain can be distinguished into two parts}

1. Medial sides:Related to wellness, they are composed by midbrain-VTA, basal ganglia, nucleus accumbens, amygdala (distinguishing fears and pleasant stimuli), some hypothalamuspineal gland nuclei, lymbic system and all the associated areas

2. Lateral sides: We have to remember that a stress stimulus can convert dopamine into cathecolamines, due to dopa-betahydroxylase, and this leads to the prevalence of lateral pathways, that brings stress signals and activate the CRH-ACTH systems in HPA axis, with an increase of cortisol for example - studies done on opioids and on acupuncture confirm that a stress can increase POMC, pro-opium-melano-cortin, and this is related to an increase of HPA and cortisol, but fortunately of dopamine too, so to re-equilibrate the pathways from lateral to medial. Opioids can also reduce gaba, so to reduce inibition of positive dopamine pathways, and they are also able to stimulate serotonine, that regulates dopamine as well.

It's also known that learning, memory, decision making, and cognitive functions are related to dopamine system. This because basal ganglia are the engine of the whole brain: they project to cortex the main part of the thought-project-action, and cortex filters and puts into action the more innate stimuli and inputs.

So, infancy is a phase in which brain is in development, and this means:

\section{1. that it is more able to adapt in order to learn the best choices}

2. that it is more at stress risk

I mean that rewarding lifestyles are fundamental for babys:

1. in order to reinforce the behaviors and learning we want to infuse to our babies

2. in order to prevent stress that is a nociceptive condition, a negative event always to prevent and evitate

3. in order to guarantee to our babies the better wellness life we can, during their childhood, and this means for their future life as well: since brain is more plastic at this age, and it is somehow marked in his main characteristics, having influence for the rest of babies years. That's why we described all the chapters of which we talked about. We focused on reward system strategies in some chapters.

\section{Diet and nutrition}

That is always a basis, since our metabolism is the fundamental basis so that every organ can have the better function it can. In this case we talked about breastfeeding, that is essential from a nutritional point of view, and also from a psychological side: since it creates correct bond and good perceptions for babies and also for mother.

Mediterrenean diet is of course a great choice: declared by UNESCO as intangible heritage of humanity, it's based on wholegrain cereals, vegetables and fruit (5 servings per day picking them from any color kind), white meats, fish, eggs, cheese, dry nuts, and a very low amount of sweet and refined foods. Making frequent breaks can also be good, but they have also to be as low as possible sweet but natural, better if water or tea with stevia, the natural sweetener.

\section{Fitness}

Physical activity is another important part of our life and lifestyle, since it reduces stress, discharging it daily, and it is also important to have the correct tonical production of opioids, that can circulate in the needed amount.

\section{Mind side}

As we said the emotions taking place in the family are the food of our soul (psychology is traditionally the study of the soul), of our istincts, of who we are. It's important that parents, since baby is in uterus, start living the correct role they are having. Couple love is basis for a correct wellness in parents life. After birth the new equilibrium is to be established: parents are both partners and caregivers to their newborn.

\section{Affective life}

For adults affective life is a daily need, and babies need to percieve love toward them as well. Parents have to establish a loving interaction in their fullfillment of baby's needs, and they also have to communicate with babies always in a loving way, to stimulate baby's growth and autonomy, teaching basic learnings, and having a loving behaviour toward their kids, playing also with them during the periods in which babies are happy to interact with adults, and promoting the interaction with babies peers. This starts when babies are 3-4years old, age in which they start playing with brothers and sisters, for example. The emotional nourishment goes on during all the school years, in which kids starts making friends and having favourite sypmathies. The role of parents is always two sided: they have to give the correct procection, so that babies feel sure and confident with the world, and they have to encourage autonomy and external relationships with friends and beloved. Affective life in adolescence and later on is also fundamental to absolve in the best way to mandatory duties of life.

\section{Any rewarding lifestyle}

Any event and habit that is able to act on medial sides of reward is to promote, since dopamine is the LIFE molecule, and it can help learning and positive growing of baby.

Having a pet is great for babies, since a pet gives immunitary help to babies and also it can help affective growth, of course it also boost responsibility since children have topersonally take care of their animals. Outdoor activities are also great: vitamin D is fundamental for development, not only of bones, and sunlight is energizing too.

It's also good that children live their school tasks in positive way: the correct amount of homeworks is basic, and also it's good that any competitive event is not seen in this way, in school environment and in sport matches too...child have to live with fun and interest any of these challenging situations. 
It is also imporant to follow traditions: both for chinese and turkish cultures it's a rule to respect that for 40days after the birth... baby and the mother don't see any people, relative or friend, but they have to stay at home so to prevent contacts with pathogens (virus, bacteria ad so on) and so to evitate stress, that is cause of course of any infection or other weakening disease (for chinese QI, energy, is one of the three treasures we have to take care of in order to be healthy); and they have to stay at home relaxing together, as we already said, in a lovely environment, ideal for them and for anyone.

A positive environment is always suggested: if we think to the growing amount of allergies and intollerances, it's obvious that in these cases stress lateral sides (as we said before) are prevalent, so that any allergen can trigger reactions, due to an altered threshold.

Always relating to that: it's clear that preferring organic foods is very important. Preservants can alter our genes (and it's also true that correct food positively act on us as well), and babies genes and cell metabolisms too, and an healthy eating lifestyle is useful and helpful to prevent childhood diabetes and obesity, associated as we said to some phyisical activity (30minutes at 6-10years, even every day; 60 minutes later on during puberty).

Establishing the correct "reward synchronies" is also great: babies have to live in the best environment that they can, free of any stress condition, and rich in positive stimuli and lifestyles. It also seems that ther can be molecular interactions starting from the months in which babies are in uterus, so even pregnancy is to protect at best: babies hear sounds and react to stimuli, any kind of condition can influence their growth.

If we talk about epigenetics, a part from the chinese saying and proverb according to which "in order to have a better life we should choose our parents", it's also true that leading a correct lifestyle during our whole life is great to guarantee the better genes we can for our babies (jing is the reproductive treasure - "anderior sky" - for chinese and it's influenced by our life, and it is transmitted to our babies, so it is to be respected according to our needs and rules): this is a topic studied and explained by epigenetics, that confirms that not only inherited genes but also environments can transform who we are in any way.

So reward is always a basis to protect our way of being and feeling, so to live in wellness as much as we can, and this is true in any phase of babies life: when they drink mother's milk and they can't talk, and during all the following years, since brain is plastic but any organ do.

Cuddling with our kids can be better than trying to explain how to solve a difficult situation they can be living: being ourselves and affective is always a behaviour to follow.

Role plays can also be important: so that babies can act more evoluted roles and use reasonings typical of more mature way of being, and this also helps responsibilities that child can start having too, and it also allows to express past, present and future parts of himself.

In younger phases i think it's better that babies and children play with real games, so that they can "touch" the effect of their action, with more positive real effects; when school ages go on virtuality can also help, so to develop abstraction thinking abilities and to expand the possibilities too.

As we said, interaction with others is good at any age: fundamental during adolescence, so to live at best the new roles that youth involves, basis for adult happy adult life; and important also during infancy and childhood, so to learn abilities and have fun at the same time. This is of course necessary to develop correct mind synchronies, with people of same age, with same needs, same thoughts, same emotions and perceptions, and lifestyles too.

We would also suggest to follow children' times: babies are never in a hurry and they tend to prefer rewarding choices for sure. Also contact with adults decrease with time, so to give time to autonomous activities, as we said, and to time to interact with other children.

Stimulating kids with some learning activities is good, and it's good to respect their preferences: for example learning to swim is important, but for TCM (traditional chinese medicine) it is also related to fertility problems during adulthood.

Talking about sport we could prefer armonious and relaxing activities, such as hatha yoga for children, that helps also respiration rythm. It's always great to favor the simple behaviour of babies and children, not complicating things with adult characteristics: this will respect common happines of kids.

CAM (complementary and alternative medicines) are of course great: they act on reward (acupuncture thanks to opioids, and all the others in similar ways, since they balance our stress systems), and it's always important that kids are protagonists of their choices.

Vaccines can also be judged in a positive way since it is enough that we compare statistical data comparing developing countries and countries in which vaccines are mandatory: it's not only a matter of hygene condition and of respect of needs rights (such as right to food).

Health is a right according to OMS and it's a complete condition of well-being. Food is a right as well. And in our opinion a good reward lifestyle is also a right, since more and more it's recognized as basis to get and maintain an healthy life condition, as we are explaining.

Education is also fundamental, and the Nobel prize winner Malala is giving messages, amongst many others, so to guarantee the right education in every world's country. Education is education to knowledge, behaviours, and also education to health, well-being and wellness, and making investments in this is fore sure more important that giving funds to last stage care systems.

Antonovsky in 1979 developed the Salutogenesis concept, according to which: at first we have to lead a correct lifestyle (as also Maslow's needs pyramid described in 1954), and then in case of any alteration from this equilibrium, we can pass to other health helping systems, where acupuncture come before medical drugs and so on. Being conscious and aware of that is key element to rule an healthy and positive lifestyle, so to get an individual, couple, family and social wellness condition.

Letting the baby dream and express his thought is also essential: it's essential to develop fantasy and creativity, and to allow him or her to realize his dreams too, that can be useful to all of us as well. Confidence and trust toward the environment are basic key element as well, so to build correct relationships during adolescence and adulthood.

Telling fables to babies and children is also good, so to teach them life in a metaphorical way. The story should be positive and compared to infant's age of course, and solutions to negative aspects in the plot should also be always given, with positive emotions transmitted. Reinforcement of positive aspects of situations is good as well, and it's fundamental to empower babies, and to create positive conditioning, judging in the better way any good behaviour they have. This can incentivate positive results at school and in any aspect of life. 
Also some abilities can be learnt, with family, with friends: such as cooking simple recipes that babies can like, or similar fundamental competences. We should remember that anyone of us has "infant moments" during our life, so learning how to approach to babies is useful not only to be good parents or babies caregivers, but it can help us being good and lovely people in any situation we can face.

We conclude the article with a short turkish story for kids by Nasreddin Hoca, born in 1208 in central Anatolia, and UNESCO declared the year 1996 in his honour, ...talking about a man saving the moon in a well, that reminds us that seeing in good way what we live is the key to happiness of all of us.

\section{Restoring the moon}

One night Hoca looked into his well and saw there the reflection of the full moon. "Oh no!" he exclaimed. "The moon has fallen from the sky and into my well!" He ran into his house and returned with a hook attached to a rope. He then threw the hook into the water and commenced to pull it up again, but it became stuck on the side of the well. Frantically the Hodja tugged and pulled with all his might. The hook suddenly came loose, and the Hodja fell over backwards, landing flat on his back. Scarcely able to move, he looked up into the sky and saw the full moon above him. "I may have injured myself in doing so," he said with satisfaction, "but at least I got the moon back into the sky where it belongs."

\section{Acknowledgments}

None.

\section{Conflicts of interest}

Author declares there are no conflicts of interest.

\section{Funding}

None.

\section{References}

1. http://www.unicef.it/

2. http://www.jn.pt/iniciativasjn/guiasdesaude/bks/08.html

3. http://www.livrarialeitura.pt/livro/tudo-sobre-amamentacao-hannahlothrop/?comment_oid=592837

4. Webster-Gandy J, Madden A, Holdsworth M (2011) Oxford handbook of nutrition and dietetics. Oxford university press, London, UK.

5. http://justcookforkids.com/blog/food-love-family-a-practical-guide-tochild-nutrition/

6. http://www.libreriauniversitaria.it/sviluppo-bambino-nascita-5-anni/ libro/9788840804231

7. http://www.ibs.it/code/9788854830202/de-pascalis-pierluigi/giovanecampione-sviluppo.html

8. http://www.editrice-esculapio.com/zappulla-pediatria-generalespecialistica/

9. http://www.ibs.it/code/9788877114518/behrman-richard-e-/nelsontrattato-pediatria.html

10. http://www.ceaedizioni.it/ita/scheda_libro.asp?idlibro=700

11. http://ilmiolibro.kataweb.it/libro/medicina-e-salute/213016/reward-ii/ 